\title{
ECLETICA
}

WWW.scielo.br/eq

Volume 30, número 2, 2005

\section{Thermal annealing effects on vanadium pentoxide xerogel films}

\author{
G. N. Barbosa ${ }^{a}$, C. F.O. Graeff ${ }^{b}$ and H. P. Oliveira ${ }^{a \dagger}$ \\ ${ }^{a}$ Depto. de Química, ${ }^{b}$ Depto. de Física e Matemática, FFCLRP, Universidade de São Paulo, Av. Bandeirantes 3900 , \\ Ribeirão Preto (SP), 14040-901, Brasil \\ +Corresponding author. Fax: +55 16 633-8151; e-mail: herepo@ffclrp.usp.br
}

\begin{abstract}
The effect of water molecules on the conductivity and electrochemical properties of vanadium pentoxide xerogel was studied in connection with changes of morphology upon thermal annealing at different temperatures. It was demonstrated that the conductivity was increased for the samples heated at $150^{\circ} \mathrm{C}$ and $270^{\circ} \mathrm{C}$ compared to the vanadium pentoxide xerogel. It was also verified a stabilization of electrochemical processes of the insertion and de-insertion of lithium ions the structure of thermally annealed vanadium pentoxide.
\end{abstract}

Keywords: vanadium pentoxide xerogel; conductivity; X-ray diffraction; electrochemistry.

\section{Introduction}

Vanadium pentoxide xerogel can be produced by sol-gel process and exhibits a layered structure, which is suitable for intercalation chemistry with a variety of inorganic and organic species maintaining its basic structural integrity during the course of reactions [1-4]. In addition, the conductivity of vanadium pentoxide xerogel enables its utilization in many systems such as rechargeable cathodic material, electrochromic devices, and electrochemical sensors [5-7]. The conduction in this transition metal oxide can be explained by thermally activated electron hopping between metallic centers in different oxidation states: hopping of unpaired electrons between $\mathrm{V}^{\mathrm{IV}}$ and $\mathrm{V}^{\mathrm{V}}$ ions [8-11]. Moreover, such gels can also be considered as hydrated oxides, and the ionic contribution to overall conduction arises from hopping of protons through the layered structure of vanadium pentoxide xerogel. Thus, the conduction within the xerogel is also determined by the intercalated water content [12-15]. Concerning the application of this material in secondary battery cathodes, vanadium pentoxide xerogel films allow the intercalation of lithium ions to maintain the electroneutrality of the system because electrons are also introduced during the intercalation reaction [6]. However, the process of lithium diffusion into the vanadium pentoxide structure is limited by solvent exchange [16], changes in volume and mechanical stress, as well as steric hindrance that induce the decrease of its charge-discharge capacity normally observed after some cycles, limiting the rechargeability [17]. In this context, the present work reports the effects of thermal annealing on electrochemical and conductivity properties of vanadium pentoxide xerogel films prepared by polymerizing decavanadic acid. In addition, the structural features as well as morphology of the samples were also investigated.

\section{Experimental}

Reagents and synthesis of $\mathrm{V}_{2} \mathrm{O}_{5} . n \mathrm{H}_{2} \mathrm{O}$

The vanadium pentoxide gel was prepared by ion exchange method as reported in the literature $[1,8]$. Sodium metavanadate (Fluka) was dissolved $(4,25 \mathrm{~g})$ in $250 \mathrm{~mL}$ of deionized water and the 
resulting solution was eluted through an ion exchange column $\left(\mathrm{H}^{+}\right.$form, Dowex-50X). A pale yellow solution of polyvanadic acid was obtained and, after several days, a red polymerized $\mathrm{V}_{2} \mathrm{O}_{5} \cdot \mathrm{nH}_{2} \mathrm{O}$ gel was formed by polycondensation at room temperature $[1,8]$. The films were obtained by the slow evaporation of the gel on a glass plate or on an ITO electrode at room temperature $\left(25^{\circ} \mathrm{C}\right)$ and in air, leading to a xerogel. The thickness of the films ranged from 2.0 ìm to 5.0 ìm and it was estimated using the optical fringe interference method [18,19].

Thermal annealing was done in air at constant temperature $\left(150^{\circ} \mathrm{C}, 270^{\circ} \mathrm{C}\right.$ and $\left.600^{\circ} \mathrm{C}\right)$ for $15 \mathrm{~min}$. The compositions of the samples used in conductivity and electrochemical studies were determined by thermal analysis:

$1-\mathrm{V}_{2} \mathrm{O}_{5} \cdot 2.1 \mathrm{H}_{2} \mathrm{O}$ (without thermal treatment, sample $\mathrm{A}_{25}$ ); 2- $\mathrm{V}_{2} \mathrm{O}_{5} \cdot 1.1 \mathrm{H}_{2} \mathrm{O}$ (thermal treatment at $150^{\circ} \mathrm{C}$, sample $\mathrm{A}_{150}$ ); $3-\mathrm{V}_{2} \mathrm{O}_{5} \cdot 0.32 \mathrm{H}_{2} \mathrm{O}$ (thermal treatment at $270^{\circ} \mathrm{C}$, sample $\mathrm{A}_{270}$ ); 4- $\mathrm{V}_{2} \mathrm{O}_{5}$ (thermal treatment at $600^{\circ} \mathrm{C}$, sample $\mathrm{A}_{600}$ ).

\section{Equipment and procedure}

The X-ray diffraction (XRD) data were recorded on a SIEMENS D5005 diffractometer using a graphite monochromator and $\mathrm{CuK}_{\mathrm{a}}$ emission lines. The samples, in film form, were obtained on a glass plate and the data were collected at room temperature over the range $2^{\circ}$ $£ 2 \mathrm{q} £ 50^{\circ}$. The transmission electronic spectra (Ultraviolet/Visible spectra) were recorded on a Varian Cary 50 spectrophotometer with the samples formed on a quartz plate (also used as the reference). Scanning electron microscopy (SEM) studies were carried out on a Zeiss DSM 940 microscope, operating at $20 \mathrm{kV}$. Electron paramagnetic resonance (EPR) spectra were obtained at room temperature using a computer interfaced Varian E-4 spectrometer operating at $9.5 \mathrm{GHz}$ (X band) and the sample (in film form) was placed in a quartz sample-holder. The infrared spectra were recorded from $2000 \mathrm{~cm}^{-1}$ to $400 \mathrm{~cm}^{-}$ ${ }^{1}$ on a BOMEM MB-100 FT-IR spectrometer. The films were dispersed in $\mathrm{KBr}$ and pressed into pellets. The thermogravimetric data were registered on a Thermal Analyst equipment model 2100-TA in air atmosphere and at a heating rate of $10^{\circ} \mathrm{C} \mathrm{min}{ }^{-1}$. Dc conductivity was measured as a function of temperature from $150 \mathrm{~K}$ to $350 \mathrm{~K}$. Measurements were done with samples in film form and were performed in an evacuated chamber using a DC bias of $1 \mathrm{~V}$ between silver electrodes. When the samples were thermally treated, the conductivity measurements were performed as soon as the samples left the furnace in order to avoid re-hydration. Electrochemical experiments were carried out with an AUTOLAB (EcoChemie) model PGSTAT30 (GPES/FRA) potentiostat/galvanostat interfaced to a computer. The conventional three-electrode arrangement was used, consisting of an ITO supporting electrode, a platinum wire auxiliary electrode and saturated calomel electrode (SCE) as reference electrode. A 0.1 moldm ${ }^{-3}$ solution of $\mathrm{LiClO}_{4}$ in acetonitrile was used as electrolyte. Experiments were carried out in deoxigenated solutions and at room temperature.

\section{Results and Discussion}

X-ray diffraction (XRD) patterns for vanadium pentoxide xerogel in the as grown and thermally annealed states are shown in Figure 1. For samples treated at $150^{\circ} \mathrm{C}$ and $270^{\circ} \mathrm{C}$ (Figures $1 \mathrm{~b}$ and $1 \mathrm{c})$, the diffraction patterns present peaks, which are broad and have low intensities, suggesting a decrease in crystallinity after thermal treatments. The XRD pattern for the sample treated at $600^{\circ} \mathrm{C}$ (Figure 1d) is characteristic of crystalline $\mathrm{V}_{2} \mathrm{O}_{5}$ phase. The shifts of 001 diffraction lines to higher $2 \mathrm{q}$ values, shown in Figure 1, indicate a gradual decrease of the interlayer spacing: $\mathrm{V}_{2} \mathrm{O}_{5} \cdot 2.1 \mathrm{H}_{2} \mathrm{O}-1.28 \mathrm{~nm} ; \mathrm{V}_{2} \mathrm{O}_{5} \cdot 1.1 \mathrm{H}_{2} \mathrm{O}-1.21 \mathrm{~nm}$; $\mathrm{V}_{2} \mathrm{O}_{5} .0 .32 \mathrm{H}_{2} \mathrm{O}-1.14 \mathrm{~nm} ; \mathrm{V}_{2} \mathrm{O}_{5}-0.42 \mathrm{~nm}$. The decrease in interlamellar spacing is related to the release of intercalated water. For the sample $\mathrm{A}_{600}$, it was verified a complete dehydration process. In addition, it should be noted that even with the thermal treatment at $270^{\circ} \mathrm{C}$, the vanadium pentoxide lamellar structure is preserved; probably because of the remaining strongly bonded water molecules that are involved in the formation of the polyoxovanadate network. 


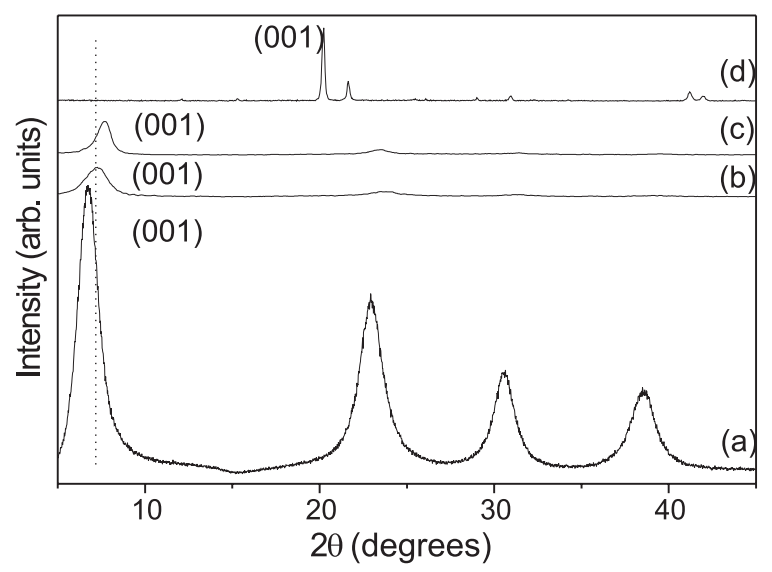

Figure 1: X-ray diffraction patterns of the hydrated vanadium pentoxide matrix sample $\mathrm{A}_{25}$ (a) and of the samples after thermal treatment at different temperatures: sample $\mathrm{A}_{150}(\mathrm{~b}), \operatorname{sample}_{270}$ (c) and sample $\mathrm{A}_{600}(\mathrm{~d})$.

The infrared spectra of the $\mathrm{V}_{2} \mathrm{O}_{5}$ xerogel and of the samples submitted to thermal annealing are illustrated in Figure 2. The strong and characteristic peaks around $1012 \mathrm{~cm}^{-1}, 763 \mathrm{~cm}^{-1}$ and a broad one at $515 \mathrm{~cm}^{-1}$ have been ascribed to the stretching vibration of the vanadyl group, the in plane and out-of plane $\mathrm{V}-\mathrm{O}-\mathrm{V}$ vibrational modes associated with the $\mathrm{V}-\mathrm{O}$ bridges, respectively [2022]. The FTIR spectra of the samples $A_{25}$ and $A_{150}$ (Figures $2 \mathrm{a}$ and $2 \mathrm{~b}$ ) present a weak peak at 923 $\mathrm{cm}^{-1}$ and two shoulders at $715 \mathrm{~cm}^{-1}$ and $678 \mathrm{~cm}^{-1}$ that are not observed in the spectrum of crystalline $\mathrm{V}_{2} \mathrm{O}_{5}$ solid. These bands are likely to be related to water molecules bonded to the vanadium pentoxide polymeric chain. The weaker peaks (715 $\mathrm{cm}^{-1}$ and $678 \mathrm{~cm}^{-1}$ ) could be related to hydrogen bonding with oxygen atoms of vanadyl group and, the band at $923 \mathrm{~cm}^{-1}$ can be assigned to the $\mathrm{V}_{-}$ $\mathrm{OH}_{2}$ stretching vibrational mode indicating the formation of coordination bonds with vanadium atoms of vanadyl groups in the interlamellar domain $[23,24]$. These results are in agreement with XRD data, i.e., when the sample is heated the interlayer water is released resulting in a smaller interlamellar distance until a new phase is formed, anhydrous $\mathrm{V}_{2} \mathrm{O}_{5}$.

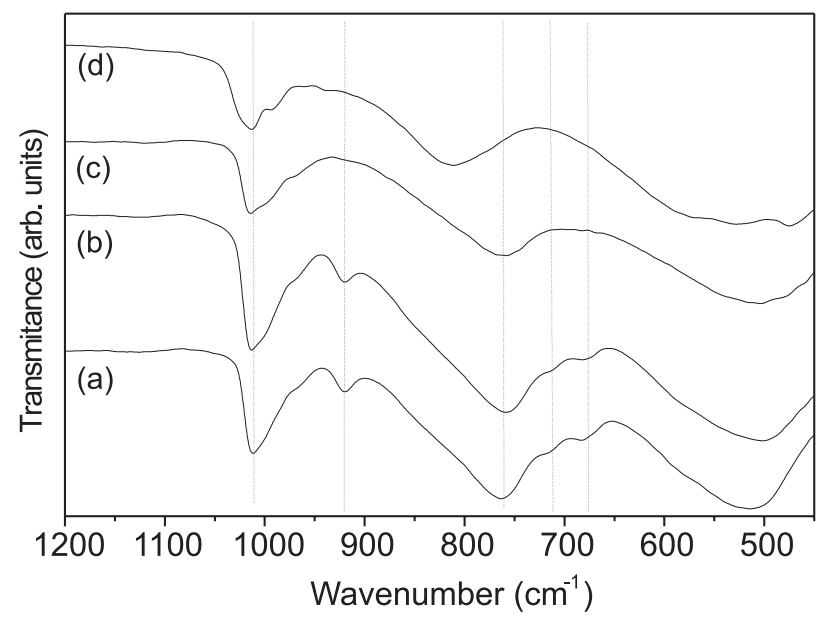

Figure 2: FTIR spectra of the hydrated vanadium pentoxide matrix sample $\mathrm{A}_{25}$ (a) and of the samples after thermal treatment at different temperatures: sample $\mathrm{A}_{150}(\mathrm{~b})$, sample $\mathrm{A}_{270}(\mathrm{c})$ and sample $\mathrm{A}_{600}(\mathrm{~d})$. 
Figure 3 shows scanning electron micrograph images of the $\mathrm{V}_{2} \mathrm{O}_{5}$ xerogel before and after the thermal annealing at different temperatures. The SEM image of the hydrated vanadium pentoxide matrix (Figure 3a) indicates the presence of a network of chains interconnected randomly $[3,25]$. An interesting point is that, despite the thermal treatment at $150^{\circ} \mathrm{C}$ and $270^{\circ} \mathrm{C}$ (Figures $3 \mathrm{~b}$ and $3 \mathrm{c}$, respectively), the samples retained the initial morphology of the $\mathrm{V}_{2} \mathrm{O}_{5}$ xerogel with no drastic distortions in the polymeric chains. On the other hand, the SEM image of the sample submitted at $600^{\circ} \mathrm{C}$ shows how the morphology changed dramatically from a network of chains to a noncontinuous surface formed by stick-like microcrystallites with $20 \mathrm{~mm}-30 \mathrm{~mm}$ of length. (a)

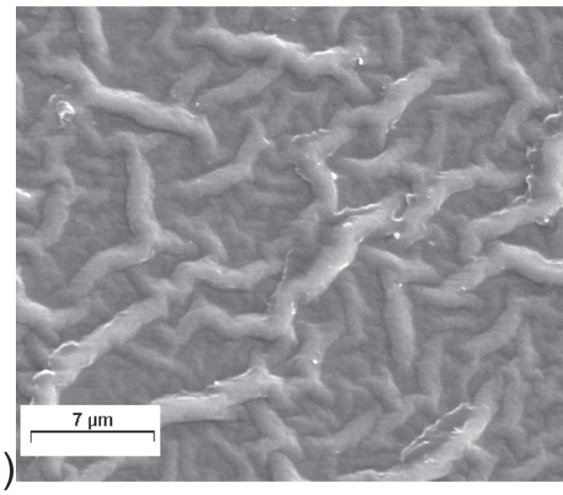

(c)

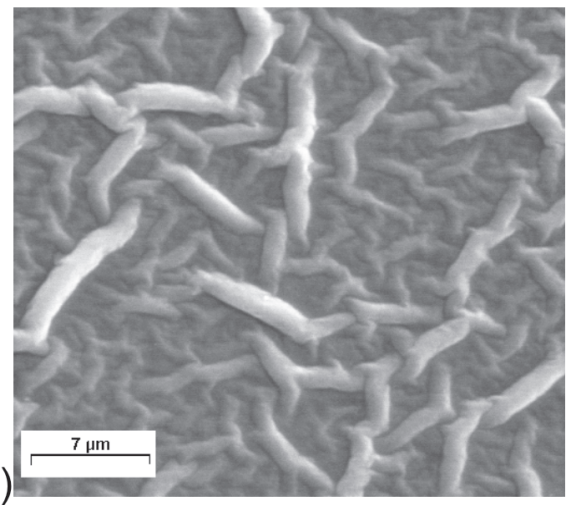

(b)

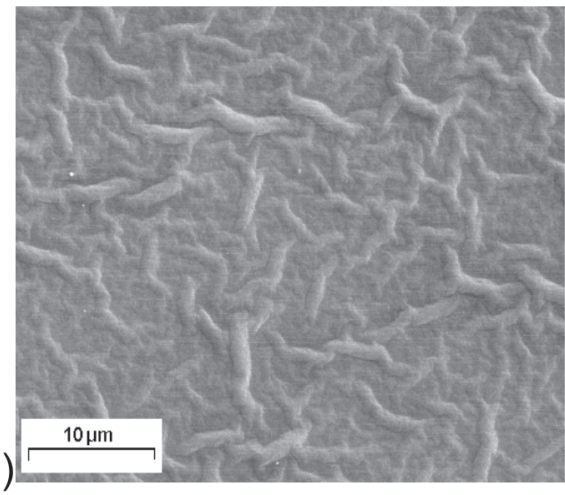

(d)

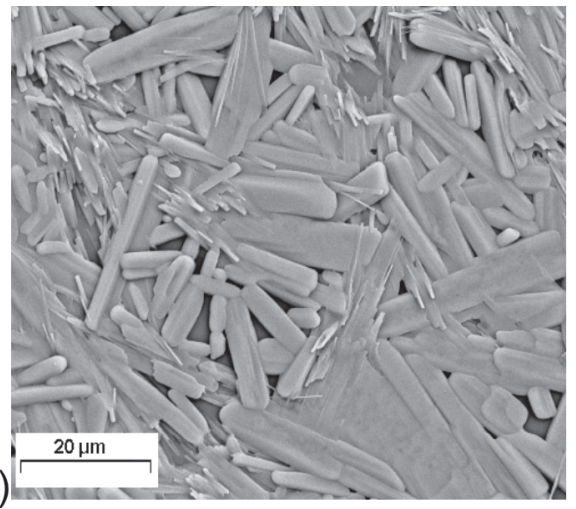

Figure 3: Scanning electron micrographs of the sample $A_{25}(a)$, sample $A_{150}(b)$, sample $A_{270}(c)$ and sample $A_{600}(d)$.

Figure 4 shows the evolution of EPR spectra obtained at room temperature for the samples before and after thermal treatment at different temperatures. For the sample without thermal treatment (Figure 4a), the EPR spectrum shows the characteristic profile that arises from the unpaired $3 \mathrm{~d}$ electron ( $\mathrm{V}^{(\mathrm{IV})}, S=1 / 2, I=7 / 2$ ) localized around vanadium centers that results in a hyperfine structure in an axially distorted crystal field $[8,26]$. After thermal treatment, a broadening of the signal can be observed up to $270^{\circ} \mathrm{C}$ (Figures $4 \mathrm{~b}$ and $4 \mathrm{c}$ ). This effect can be explained by the reduction of $\mathrm{V}^{\mathrm{V}}$ to $\mathrm{V}^{\mathrm{IV}}$ which enhances the spin-spin exchange interaction, i.e., as the content of $\mathrm{V}^{\mathrm{IV}}$ increases the hyperfine EPR interactions tend to disappear. By comparison with previous results reported in literature [24], it can be inferred that after the thermal treatment at $270^{\circ} \mathrm{C}$ the ratio of $\mathrm{V}^{\mathrm{IV}} /\left(\mathrm{V}^{\mathrm{V}}+\mathrm{V}^{\mathrm{IV}}\right)$ is at least $16 \%$. It should be noted that for the highest annealing temperature no EPR signal was observed (Figure 4d), which is an indication of the oxidation of $\mathrm{V}^{\mathrm{IV}}$ centers during the crystallization process. 


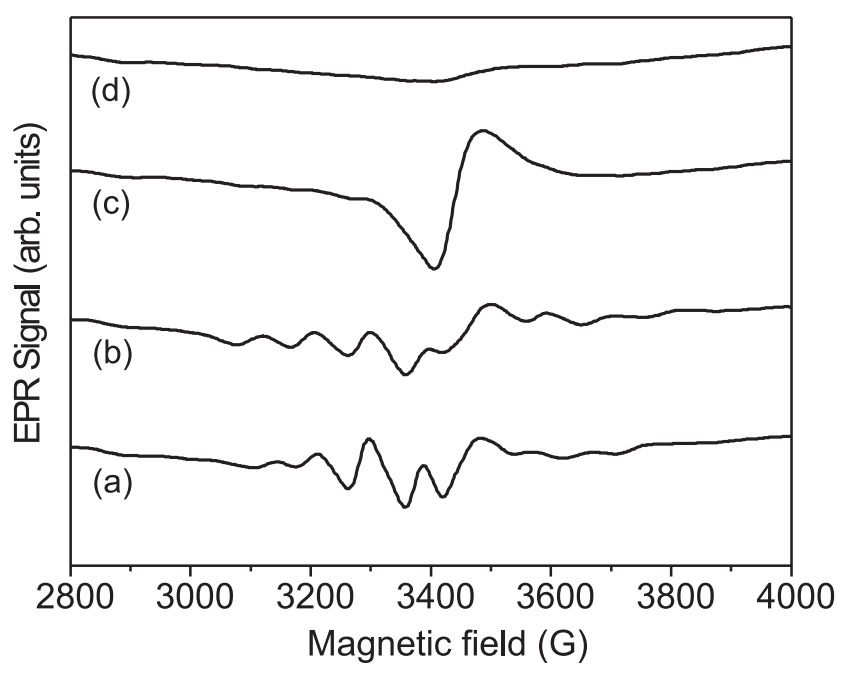

Figure 4: EPR spectra at room temperature of the sample $A_{25}(a)$, sample $A_{150}(b)$, sample $A_{270}$ (c) and sample $\mathrm{A}_{600}(\mathrm{~d})$.

The electronic spectra of the vanadium pentoxide xerogel and of the samples submited to heating are shown in Figure 5. The UV/Vis spectra of the vanadium pentoxide xerogel and of the sample heated at $270^{\circ} \mathrm{C}$ shows an absorption band at 384 nm attributed to vanadium (V)-oxide charge transfer (CT) transition $[4,8]$. This transition intensity decreases upon thermal treating, suggesting that upon heating $\mathrm{V}^{\mathrm{V}}$ centers are reduced to $\mathrm{V}^{\mathrm{IV}}$. This result in is agreement with that reported in the literature, i.e., dehydration of $\mathrm{V}_{2} \mathrm{O}_{5} \cdot \mathrm{nH}_{2} \mathrm{O}$ gels leads to some reduction of vanadium ions $[1,27]$. Whereas, for the sample treated at $600^{\circ} \mathrm{C}$, the intensity of CT band increased with a bathochromic shift, indicating the oxidation of vanadium $\mathrm{V}^{\mathrm{IV}}$ sites, in good agreement with the EPR results.

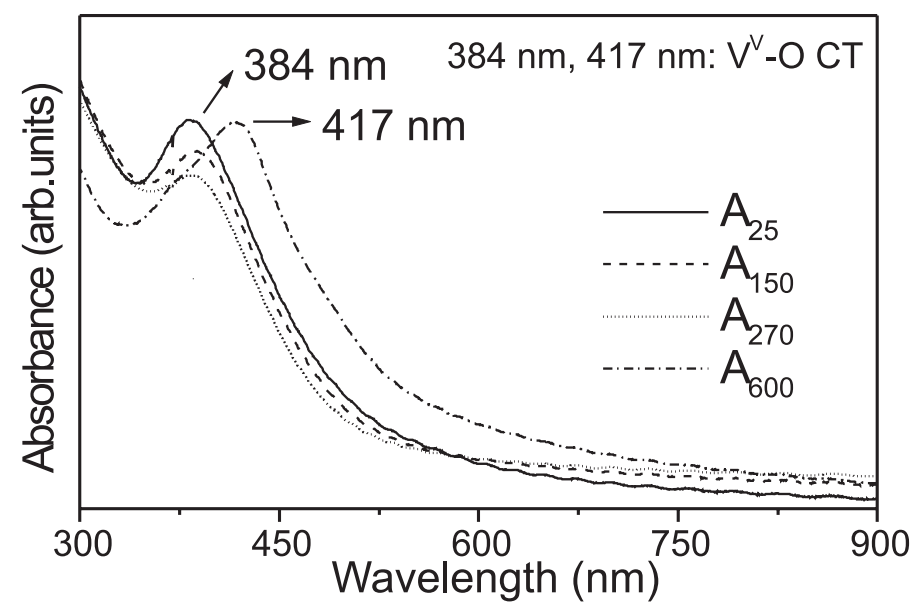

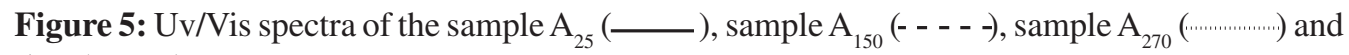
sample $\mathrm{A}_{600}(\cdot-\cdot-\cdot)$. 
Thermal annealing affects the electrical conductivity, as shown in Figure 6. The conductivity increases upon thermal treatment up to $270^{\circ} \mathrm{C}$ : the room temperature conductivity changed from $2.23 \pm 0.04 \times 10^{-2}(\mathrm{~W} \mathrm{~cm})^{-1}$ to $3.80 \pm 0.07 \times 10^{-2}(\mathrm{~W} \mathrm{~cm})^{-1}$ for the sample treated at $270^{\circ} \mathrm{C}$. The activation energy also changed from $0.29 \pm 0.03 \mathrm{eV}$ in $\mathrm{V}_{2} \mathrm{O}_{5} \cdot 2.1 \mathrm{H}_{2} \mathrm{O}$ to $0.24 \pm 0.02$ in $\mathrm{V}_{2} \mathrm{O}_{5} \cdot 0.32 \mathrm{H}_{2} \mathrm{O}$. On the other hand, it was verified a decrease in conductivity for anhydrous $\mathrm{V}_{2} \mathrm{O}_{5}$ $\left(4.07 \pm 0.08 \times 10^{-3}\left(\mathrm{~W} \mathrm{~cm}^{-1}\right)\right.$. The changes observed in conductivity (Figure 6) may arise from different factors: from the small polaron model [28], the activation energy $(W)$ of the conductivity at higher temperatures reflects the contributions from the polaron binding energy, the structural disorder, as well as the transfer integral (the coupling potential between two hopping sites). In the case of $\mathrm{V}_{2} \mathrm{O}_{5}$ xerogel, it is especially difficult to separate these contributions to the activation energy, which can vary from $0.17 \mathrm{eV}$ to $0.65 \mathrm{eV}$ [29]. Higher activation energy is normally attributed to the disorder term. In our system, the disorder has indeed increased with the heating as shown by XRD data (Figure 1) and SEM images (Figure 3), which clearly does not explain the decrease in activation energy for samples heated by $270^{\circ} \mathrm{C}$. Thus, assuming that the small polaron hopping model is valid, which may not be the case since our samples are clearly inhomogeneous, a possible explanation comes from a change in the potential barrier sensed by the electron due to the increase in the density of $\mathrm{V}^{\mathrm{IV}}$ sites as verified by EPR and electronic spectra (Figures 4 and 5, respectively), i.e., an increase of smallpolaron transfer from one vanadium ion to another $[8,11,30]$. Another interesting point is that the SEM images did not show any drastic changes in the film morphology for treatments up to $270^{\circ} \mathrm{C}$ (Figures 3a-3c). However, for higher treatment temperatures crystalline $\mathrm{V}_{2} \mathrm{O}_{5}$ domains appeared (Figure 3d). Therefore, from a morphological point of view, it is not expected that treatments below $270^{\circ} \mathrm{C}$ should influence the conductivity as a consequence of loss in polymeric chains connectivity. However, for treatments above $270^{\circ} \mathrm{C}$ the decrease in conductivity for anhydrous vanadium pentoxide could be related to changes in the film structure and the formation of aggregates consisted of small and large particles that reduce the connectivity of the sample.

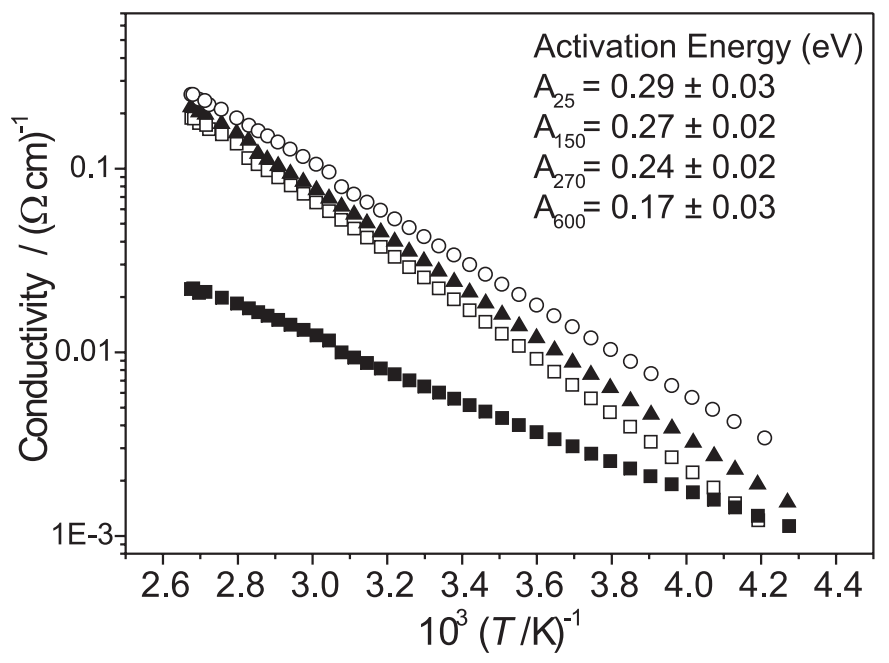

Figure 6: Temperature dependence of the electrical conductivity of the hydrated vanadium pentoxide matrix and of the de-hydrated samples after thermal treatment at different temperatures: $A_{25}(\square \square \square)$, sample $\mathrm{A}_{150}(\boldsymbol{\Delta} \mathbf{\Delta} \mathbf{\Delta})$, sample $\mathrm{A}_{270}(\mathrm{O} O)$; and sample $\mathrm{A}_{600}(\mathbf{\square} \mathbf{\square})$. 
From what is found in the literature [1,8,31], we can assume that $\mathrm{V}^{\mathrm{IV}}$ center is surrounded by six oxygen ions and presents a similar structure with the vanadyl ion $\left(\mathrm{VO}^{2+}\right)$, which has a short double bond perpendicular to four VO coplanar bonds. It also has a sixth weak bond with a water molecule oxygen localized at the opposite side of $\mathrm{V}=\mathrm{O}$. In addition, vanadium pentoxide gels are made of polymeric species containing negative charged ribbons represented by $\mathrm{V}-\mathrm{OH}$ bonds and that the electric neutrality of the compound is maintained with $\mathrm{H}_{3} \mathrm{O}^{+}$species [6,27]. In this picture, a possible explication for the slight increase of $\mathrm{V}^{\mathrm{IV}}$ centers with the increase of the temperature comes from the oxidation of $\mathrm{OH}^{-}$forming molecular oxygen as shown in the following reactions [27]:

$$
\begin{aligned}
& 2 \mathrm{OH}^{-} \rightarrow \mathrm{H}_{2} \mathrm{O}+1 / 2 \mathrm{O}_{2}+2 \mathrm{e}^{-} \\
& 2 \mathrm{~V}^{5+}+2 \mathrm{e}^{-} \rightarrow 2 \mathrm{~V}^{4+}+\mathrm{H}_{2} \mathrm{O}+1 / 2 \mathrm{O}_{2}^{-} \\
& 2 \mathrm{~V}^{5+}+2 \mathrm{OH}^{-} \rightarrow 2 \mathrm{~V}^{4+}+\mathrm{H}_{2} \mathrm{O}+1 / 2 \mathrm{O}_{2}
\end{aligned}
$$

Another explication is that during heating under oxygen containing atmosphere and in presence of water molecules, $\mathrm{V}^{\mathrm{IV}}$ sites are created together with anion vacancies: $\mathrm{O}^{2-}$ ions and hydroxyl groups on oxygen sites [32]. It should be noted that some reports demonstrated that the conductivity of vanadium pentoxide films is determined by intercalated water molecules content [12-15]. The release of water molecules induced the decrease of conductivity and the effect was more pronounced when strongly bonded water molecules were removed. In other words, it was proposed that the electrical conduction has the contribution of hopping of $\mathrm{H}^{+}$through the hydrogen bonds, i.e., it occurs only when the neighboring water molecule takes suitable orientation to form hydrogen bonding [12-15].

Cyclic voltammograms of the vanadium pentoxide xerogel after thermal annealing at $150^{\circ} \mathrm{C}$ are shown in Figure 7. The cyclic voltammogram is similar to that of vanadium pentoxide xerogel without thermal annealing [3,4,6] and exhibits anodic and cathodic peaks in the potential range $0.60 \mathrm{~V}$ to $+1.00 \mathrm{~V}$ (SCE). These peaks are ascribed to the $\mathrm{V}^{\mathrm{V}} / \mathrm{IV}$ redox pair due to the insertion and deinsertion of lithium ions $\left(x \mathrm{e}^{-}+x \mathrm{Li}^{+}+\mathrm{V}_{2} \mathrm{O}_{5} \cdot \mathrm{nH}_{2} \mathrm{O} \mathrm{D}\right.$ $\left.\mathrm{Li} x \mathrm{~V}_{2} \mathrm{O}_{5} \cdot \mathrm{nH}_{2} \mathrm{O}\right)$ in two non-equivalent sites in the vanadium oxide xerogel $[6,16,33]$. The width and asymmetric pattern of waves can be related to heterogeneity of the film surface and to the low rate of electronic transfer $[16,33]$.

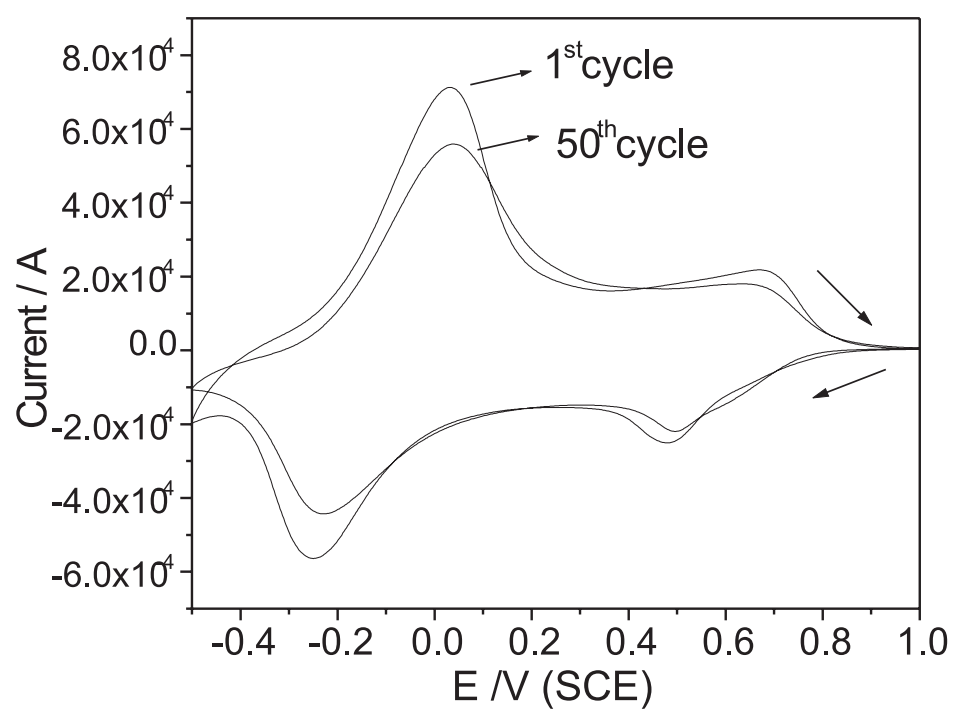

Figure 7: Cyclic voltammogram of the vanadium pentoxide xerogel after the thermal annealing at $150^{\circ} \mathrm{C}$. A $0.1 \mathrm{~mol} \mathrm{dm}^{3}$ solution of $\mathrm{LiClO}_{4}$ in acetonitrile was used as electrolyte in the potential range $+1.00 \mathrm{~V}$ to $0.60 \mathrm{~V}(\mathrm{SCE})$ and $v=100 \mathrm{mV} / \mathrm{s}$. 
For vanadium pentoxide xerogel without thermal annealing $[6,16,17]$, it is observed a pronounced decrease in total charge after several cycles. The origin of this effect can be credited to structural changes that results from either insertion and release of solvent during the lithium ion intercalation or the formation of $\mathrm{Li} x \mathrm{~V}_{2} \mathrm{O}_{5}$ stable crystalline phases, making the release of lithium ions to the supporting electrolyte solution more difficult $[16,17]$. On the other hand, for samples submitted to thermal annealing (shown in Figure 7), an increase in stability is observed in the electrochemical response with a low decrease in total charge (D»13\%), whereas for vanadium pentoxide xerogel the total charge can decrease up to $70 \%$ [4]. This variation could be related to either difference in the preparation of the material or water content and due to different synthetic procedures $[1,6,16]$. The higher stability during potential cycling can be a consequence of a better electromigration of solvated lithium ions during the intercalation and de-intercalation processes. The release of weakly bonded water molecules, probably results in a higher free volume within the interlamelar spacing that enable an easier intercalation and accommodation of the solvated ions. In addition, during the de-intercalation reaction, the release of solvated ions is also facilitated and hence offers a good cyclability to the oxide [34]. It should be noted that the electrochemical changes occurred in a material whose structural integrity was only slightly affected; X-ray diffractograms indicates a decrease in cristallinity and a decrease in interlamelar spacing after thermal annealing. Another aspect to be noticed is that the stability of the charge/discharge process can be related to an enhanced $\mathrm{Li}^{+}$diffusion through the film due to a decrease in steric hindrance of water molecules into the vanadium pentoxide xerogel bi-dimensional structure.

\section{Conclusions}

It was demonstrated that the conductivity and electrochemical properties of vanadium pentoxide films are dependent on water content. The removal of weakly bonded water molecules from vanadium pentoxide xerogel by thermal annealing at low heating rates results in an increase in conductivity with only small changes in morphology for temperatures up to $270^{\circ} \mathrm{C}$. The release of water molecules by heating is responsible for a reduction of $\mathrm{V}^{\mathrm{V}}$ centers to $\mathrm{V}^{\mathrm{IV}}$, as demonstrated by EPR and UV/Vis spectra. Thus, this set of experiments reveals that the conduction of this material is primarily determined by the hopping process of unpaired electron between $\mathrm{V}^{\mathrm{IV}}-\mathrm{V}^{\mathrm{V}}$ centers, while the contribution of proton hopping to the conductivity is not so decisive. In addition, the stabilization in lithium electromigration was observed after thermal annealing.

\section{Acknowledgements}

This work was supported by FAPESP ( $\mathrm{n}^{\circ}$. 01/01527-5). The authors thank C.A. Brunello for EPR and conductivity measurements.

Recebido em: 17/11/2004

Aceito em: 10/01/2005

G. N. Barbosa, C. F.O. Graeff and H. P. Oliveira. Efeito do tratamento térmico nas propriedades dos filmes de pentóxido de vanádio xerogel.

Resumo: A influência da quantidade de água nas propriedades condutoras e eletroquímicas no pentóxido de vanádio xerogel foi estudada juntamente com as mudanças morfológicas com o tratamento térmico em diferentes temperaturas. Foi verificado o aumento da condutividade para as amostras submetidas a $150^{\circ} \mathrm{C}$ e $270^{\circ} \mathrm{C}$, quando comparadas com o pentóxido de vanádio xerogel sem o tratamento térmico. Foi observada a estabilização do processo eletroquímico de intercalação e desintercalação de íons lítio na estrutura do óxido de vanádio após o tratamento térmico.

Palavras-chave: xerogel de pentóxido de vanádio; condutividade; difração de raios X; eletroquímica. 


\section{References}

[1] J. Livage, Chem. Mater. 3 (1991) 578.

[2] M.G. Kanatzidis, C.G. Wu, H.O. Marcy and C.R. Kannewurf, J. Am. Chem. Soc. 111 (1989) 4139.

[3] F. Huguenin, R.M. Torresi, D.A. Buttry, J. Electrochem. Soc. 149 (5) (2002) A546.

[4] H.P. Oliveira, C.F.O.Graeff, C.L.P.S. Zanta, A.C. Galina, P.J. Gonçalves, J. Mater. Chem. 10 (2000) 371.

[5] C.M. Lampert, Solar Energy Mater. 11 (1984) 1.

[6] R.Baddour, J.P. Pereira-Ramos, R. Messina and J. Perichon, J. Electroanal. Chem. 314 (1991) 81.

[7] V. Glezer and O. Lev, J. Am. Chem. Soc. 115 (1993) 2533.

[8] N. Gharbi, C. Sanchez, J. Livage, J. Lemerle, L. Nejem and J. Lefebvre, Inorg. Chem. 21 (1982) 2758.

[9] J. Livage and R. Collongues, Mater. Sci. Eng. 23 (1976) 297.

[10] J. Bullot, O. Gallais, M. Gauthier and J. Livage, App. Phys. Lett. 36 (1980) 986.

[11] C. Sanches, F. Babonneau, R. Morineau, J. Livage, J. Bullot, Phil. Mag. 47 (1983) 279.

[12] T. Szörényi, K. Bali, I. Hevesi, J. Physique 46 (1985) 473.

[13] K. Bali, L.B. Kiss, T. Szörényi, M.I. Török, I. Hevesi, J. Physique 48 (1987) 431.

[14] J.C. Badot, A. Fourrierlamer, N. Baffier, J. Physique 46 (1985) 2107.

[15] S. Kittaka, H. Hamagushi, T. Shinno, T. Takenaka, Langmuir 12 (1996) 1078.

[16] K.West, B. Zachau-Christiansen, T. Jacobsen, S. Skaarup, Electrochim. Acta 38 (1993) 1215.

[17] J. Scarminio, A. Talledo, A.A. Andersson, S. Passerini, F. Decker, Electrochim. Acta 38 (1993) 1637.
[18] F.J. Anaissi, Nanocompósitos de Ftalocianinas e Xerogéis de Pentóxido de Vanádio (V), Thesis, Universidade de São Paulo, Instituto de Química, 1996.

[19] K.E. Stine, Beckman Infrared Laboratory Manual, Beckman Instruments Inc, 1970.

[20] C. Sanchez, J. Livage, G. Lucazeau, J. Raman Spect. 12 (1982) 68.

[21] L. Abello, G. Lucazeau, J. Chim. Phys. 81 (1984) 539.

[22] L. Abello, E. Husson, Y. Repelin, G. Lucazeau, J. Solid State Chem. 56 (1985) 379.

[23] Y. Repelin, E. Husson, L. Abello, G. Lucazeau, Spectrochim Acta A 41 (1985) 993.

[24] V. Petkov, P.N. Trikalitis, E.S. Bozin, S.J. Bollinge, T. Vogt and M.G. Kanatzidis, J. Am. Chem. Soc. 124 (2002) 10157.

[25] J.K. Bailey, G.A. Pozarnsky, M.L. Mecartney, J. Mater. Res. 7 (1992) 2530.

[26] F. Babonneau, P. Barboux, F.A. Josien, J. Livage, J. Chim. Phys. 82 (1985) 761.

[27] L. Znaidi, N. Baffier, M. Huber, Mat. Res. Bull. 24 (1989) 1501.

[28] I.G. Austin, N.F. Mott, Adv. Phys. 18 (1969) 41.

[29] M. Sayer, A. Mansingh, J. Non-Cryst. Solids 58 (1983) 91.

[30] C.H. Chung and J.D. Mackenzie, J. Non-Cryst. Solids 42 (1980) 357.

[31] C.J. Ballhausen, H.B. Gray, Inorg. Chem. 1 (1962) 111. [32] K.E. Swider-Lyons, C.T. Love, D.R. Rolison, Solid State Ionics, 152 (2002) 99.

[33] M. Nabavi, S. Doeuff, C. Sanches, J. Livage, Mater. Sci. Eng. B 3(1-2) (1989) 203.

[34] E. Shouji, D.A., Buttry, Electrochim. Acta 45 (2000) 3757. 